\title{
"You Want Me to Come to Your Office?!": Student experiences of Moving from Failure to Success in a Nursing Course
}

\author{
Sonya L. Jakubec \\ Mount Royal University, sjakubec@mtroyal.ca \\ Joanne Bouma \\ Mount Royal University, jbouma@mtroyal.ca \\ Joseph Osuji \\ Mount Royal University, josuji@mtroyal.ca \\ Mohamed T. El Hussein \\ Mount Royal University, melhussein@mtroyal.ca
}

Follow this and additional works at: https://qane-afi.casn.ca/journal

Part of the Higher Education and Teaching Commons, Nursing Commons, and the Scholarship of Teaching and Learning Commons

\section{Recommended Citation}

Jakubec, Sonya L.; Bouma, Joanne; Osuji, Joseph; and El Hussein, Mohamed T. (2020) "'YYou Want Me to Come to Your Office?!": Student experiences of Moving from Failure to Success in a Nursing Course," Quality Advancement in Nursing Education - Avancées en formation infirmière: Vol. 6: Iss. 1, Article 6.

DOI: https://doi.org/10.17483/2368-6669.1205

This Article is brought to you for free and open access by Quality Advancement in Nursing Education - Avancées en formation infirmière. It has been accepted for inclusion in Quality Advancement in Nursing Education - Avancées en formation infirmière by an authorized editor of Quality Advancement in Nursing Education - Avancées en formation infirmière. 
"You Want Me to Come to Your Office?!": Student experiences of Moving from Failure to Success in a Nursing Course

\section{Cover Page Footnote}

The authors acknowledge the support of Mount Royal University's Institute for Scholarship of Teaching and Learning for the financial and academic support of the project from which this article was developed. 
Undergraduate nursing students are generally successful in their programs, measuring success by courses passed, program benchmarks met, graduation, and good scores on licensing exams. Diverse experiences and variables of overall program attrition (the numbers of students who enter but do not complete their programs) are widely studied with institutional interest; however, understanding of how and why students do not succeed remains insufficient (Jeffreys, 2012). While, certainly, some students struggle with concepts, and others fail courses during their programs, the majority of students who fail a required course, for the most part, eventually do complete their programs and graduate. Success and failure are realities of any academic program, and nursing programs are no exception (Jeffreys, 2014; Karsten \& DiCicco-Bloom, 2015).

Students who struggle to successfully complete a course may find themselves repeating or "just passing," focusing on the pass as opposed to optimizing their knowledge and learning (Jeffreys, 2014). The practices of "just passing" and "failing to fail" students have consequences for professional education and practice (Docherty, 2018; Finch \& Taylor, 2013; Luhanga et al., 2014; Yepes-Rios et al., 2016). Nurse educators and students alike are challenged to reach beyond minimal expectations towards the goal of strong foundational knowledge. Educators hope that, with a strong foundation, nursing students will remain motivated to learn and build on their strengths throughout their careers (Jeffreys, 2012, 2014), and will gain the lifelong learning habits required as a continuing professional nursing competency (Canadian Nurses Association, 2015).

When nursing students fail a required course, they have to repeat and pass it to proceed in their program. Complicating matters, many courses may only be offered once during a year, delaying student progression and creating scheduling and program management challenges. Further, colleges or universities commonly place a time limit on progression through a program and limit the number of times a course may be repeated. This will mean that some students who have strong capacities and potential, and who may have devoted considerable time and held spaces within a program, will not complete their programs, reducing graduation rates and practicing professionals for the field. The consequences for students and the profession are considerable and, in an increasingly student-centred university environment, this exploration of student perspectives of moving from failure to success is timely and warranted (Freeman \& All, 2017).

Attrition and retention are widely examined in the nursing literature in relation to nonacademic, instructional, and institutional issues, with solutions such as support for study and time management skills; pacing; early identification for support programs; and focused program advising and admission criteria all recommended (Freeman \& All, 2017; Lancia et al., 2018; Olsen, 2017). In this paper, we present results from an interpretive phenomenological exploration of students' experiences of moving from failure to success in a nursing course. The factors related to overall program success are assessed at the level of specific courses and individual student experiences. While these findings have implications in part for institutions, they are of primary interest to nurse educators for pedagogical practice and the growing scholarship of teaching and learning.

\section{Background}

Student success throughout their nursing programs can be negatively impacted by a variety of underlying factors (Dante et al., 2011; Lancia et al., 2013). Knepp (2012) established that university students are increasingly diverse, under-prepared for university-level work, and often juggling multiple life roles involving relationships and employment. Older students may have been away from a structured learning environment for a prolonged time, and younger students 
experience transition shock as they realize that the academic expectations and mode of content delivery in a postsecondary environment is substantially different, with increased expectations from that of the high school milieu (Fay et al., 2017).

Several conceptual variables are implicated as determinants of success or failure in postsecondary education. The experience of self-efficacy and finding relevance (in particular in relation to bioscience knowledge) has been directly linked to academic success for nursing students in a prospective correlational survey study (Andrew et al., 2015). Schneider and Preckel's (2017) systematic review also found that self-efficacy plays a key role in academic success in postsecondary education. Students with low self-efficacy tend to experience myriad challenges when they fail in comparison to their peers with high self-efficacy, who often attribute their failure to measurable reasons, such as not studying enough or working a lot (Handwerker, 2018).

Another concept that plays a role in students' academic progress is self-regulation, perceived as insight into how they learn best to achieve predetermined goals while continuously self-evaluating and reflecting on performance (Wibrowski et al., 2017). Self-regulated learners tend to make academic progress based on the feedback they receive and through integration and refinement of their learning habits with that feedback (Wibrowski et al., 2017). In their longitudinal study of first-year students, using self-reported motivational and pattern measures, Wibrowski, Matthews, and Kitsantas (2017) found that students seeking formal assistance in study habits developed improved self-regulation in terms of goal directedness, awareness of their own learning process, self-efficacious beliefs, and management of their environment to establish success. Interestingly, student motivation for the maintenance of these self-regulating practices endured throughout a university program (Wibrowski et al., 2017).

A variety of interventions can be implemented with a student to avert academic failure (Vinales, 2015). The socio-critical aspects of feedback and the experiences of struggling students not seeking feedback are almost absent in the literature, in particular, descriptions of student experiences (Kerssen-Griep \& Terry, 2016). We believe that early feedback focused on students at risk can mitigate the chances of failure in a specific course and that intentional and directed feedback is a catalyst for academic success. In addition, when students receive constructive and thoughtful feedback, they tend to gain a richer and deeper understanding of concepts (Tower, et al., 2015). The goal of feedback is to minimize conceptual gaps and decrease the discrepancy between students' understanding of course content and the desired course expectations (Freitas \& Leonard, 2011; Parker \& Winstone, 2016). Failing to seek, integrate, and adopt feedback increases the risk of failure and widens the conceptual gaps and the journey from failure to success (Lammers, 2016).

The terms learning styles or study habits define how learners assimilate knowledge through a process that starts with focusing to cognitively engage and retain new information (Kirschner, 2017). It is expected that adult learners in postsecondary institutions should have developed efficient study skills and acquired appropriate learning strategies to adapt to postsecondary education. In addition to meeting the expectations of being a university student, nursing students are expected to develop critical thinking and decision-making skills that are vital for their academic success. The expectations can overwhelm some nursing students, creating dysfunctional anxiety and increasing the risk of failure. Thus, ability and speed of adjustment play a crucial role in student success (Karsten \& DiCicco-Bloom, 2015). Some skills and aspects of student development emerge through experiencing academic failure, and failure even provides some students with insight into learning strategies and their individual learning styles, as well as stronger 
comprehension of course content. Indeed, students often embark on a journey of reflection after a failure to dissect the root causes (Karsten \& DiCicco-Bloom, 2015). Such reflections, when guided respectfully and openly, and ultimately acted upon, can catalyze eventual success if the student is in a position to follow through and engage with new strategies.

The cultural and linguistic diversity in Canadian society is reflected in the demographic profile of students enrolled in nursing programs and is a significant factor in determining students' ability to fit and adapt in postsecondary educations (Miller, 2017). A 2016 Canadian review examined contributors to academic failure in postsecondary education (da Silva \& Ravindran, 2016). These authors found that the ability of students to fit in, adapt, and belong in postsecondary learning environments were key factors in determining program success (da Silva \& Ravindran, 2016). Further highlighted was the significance of language proficiency in enhancing academic performance, with poor language skills associated with higher failure rates. They concluded that failure is multifactorial in postsecondary education, including but not limited to psychological, social, cultural, and financial circumstances, and they identified a knowledge gap and absence of concrete evidence about the factors that lead to failure in postsecondary education. This gap points to the need for our study, which aimed to understand two main questions: what are students' views on their experience of moving from failure to success, and what are the individual and contextual variables students believe influence the process?

While contextual variables have been considered in previous research, little has been studied in terms of nurse educator experiences. Litchfield's (2001) small qualitative study examined five lecturers' perspectives of support for failing students, highlighting inconsistencies in addressing the issue, and pointing to the direction for future analysis. Even less is known, however, about students' perspectives, especially in describing what this experience means to them. Handwerker (2018) examined the challenges for students returning to a course or program after failure; however, no studies to date have examined the experiences of moving from failure to success and the factors nursing students believe contribute to their eventual success in courses they previously failed.

\section{Methods}

\section{Study Approach}

This study specifically sought to explore students' perspectives about the experience of successfully repeating a nursing course - achieving success after failure. Qualitative, co-created approaches to knowledge making (Denzin \& Lincoln, 2017), inspired by student-centred learning perspectives and phenomenological philosophy, provided the guiding framework for this project. Understanding the question of how students interpret their learning from failure to success necessitates an inquiry guided by a student-centered perspective of teaching and learning (Boud \& Soler, 2016). The perspective guides the research design and the analysis, instructing researchers to pay attention to the ways students determine how they learn and make their learning meaningful both within the course and extending into future practice (Bastable, 2018; Boud \& Soler, 2016). A research approach and analysis concerned with student-centred learning is one way to build contextually relevant, mutually developed knowledge and acquire important skills for nursing education, such as reflection, critical thinking, independence, and lifelong learning (Attard et al., 2010; Boud \& Soler, 2016). In this study, interviewing students about their experiences of successfully completing a course after failure emphasizes that students are indeed key informants about their role as co-learners with us as researchers and educators. 
Phenomenological knowledge has implications for teaching and learning practice in that it can reveal the heart of matters, to the lifeworld and personally relevant experiences of students as they engage with faculty and with learning activities (Greenberg et al., 2019). To explore and understand the ways people construct meaning from their experiences, interpretations, and perceptions, the guiding interpretive phenomenological methodological approach informed all aspects of our study design (Smith et al., 2009). This choice of interpretive phenomenological analysis (IPA) was particularly suited to our exploration of students' emotionally charged experiences and their attempts to understand the complex learning that takes place in the transition from failure to success. It was expected that analysis of nursing students' stories would provide the strongest insights into how they experienced failure, making sense of the world through language, discourse, experiences, and perceptions. As researchers interested in co-creation of knowledge, our roles were to combine the students' stories of their experiences with our desires for the structuring of knowledge for teaching-learning and for the profession of nursing (Thorne, 2013).

\section{Setting and Recruitment}

This study took place during the 2016-17 academic year at an undergraduate, urban university in a mid-size city in western Canada. All students enrolled in the nursing program were invited via email to participate in the study; this was complemented with a snowball sampling strategy whereby participants referred other students to the researchers and encouraged them to participate in the study. The only criteria for inclusion was that students had successfully repeated a course in the program. Since students who have failed a course are not easily located and tend not to declare themselves, it was pragmatic to reach students through other students in similar situations (Sadler et al., 2010). Informed consent was obtained, and participants were not interviewed by the instructor with whom they were taking a course at the time. Ethical approval for this study was obtained from the relevant university human ethics review board.

\section{Data Collection}

Ten students consented to participate in our study. Two of the participants identified as male and eight as female, with the age range from 21 to 43 years old. One student had English as an additional language (EAL), four were visible minorities, one was a recent immigrant to Canada, and one was Indigenous (belonging to a First Nation). Data were collected through in-depth individual interviews with open and direct questions (DiCicco-Bloom \& Crabtree, 2006). Face to face, semi-structured interviews were conducted with students in a private setting. Interviews of approximately 45 minutes were conducted by the lead investigator and held in a private meeting room on the university campus. All interviews were digitally recorded and transcribed verbatim by a contracted transcriptionist.

In the interviews, participants who had experienced failure and then success were specifically asked to describe their experience of successfully repeating a course and what made the difference for them the second time. As the interviews progressed, the researcher employed more focused questions as similar themes emerged in each interview. Interview questions were guided by the interpretive phenomenological approach, inviting participants to reflect on their own experience from the beginning and attempting to make meaning of their journey from failure to success. To start, the interviewer inquired, "Can you take me back to when you started to realize you were going to fail and what that was like for you?" The interviews unfolded thereafter in a conversational style as each participant told their story from the beginning, when they started to 
recognize that they were facing a failure through to their experience of repeating the course successfully. Participants were specifically asked to "describe your experience of successfully repeating the course, and what was different in your second attempt that contributed to your success." In this way the complex process of achieving success was explored and, in part, interpreted by the participants. Key excerpts from these accounts are provided later in this report.

\section{Analytic Strategies}

IPA is characterized by the identification of and establishment of patterns, themes, and larger interpretation (Smith et al., 2009), in this case interpretation of student experiences from failure to success. Consistent with interpretive phenomenology, data analysis proceeded with reflexivity throughout the process of the questions, to the design, to the interview questions, to the analysis, and so on. This interpretive nature of questioning, reading, and verifying data resulted in the development of new understandings for the researchers, who continually questioned preconceptions in a reflexive process and interpretations beyond thematic descriptions (Smith \& Osborn, 2003). With the first two authors describing themes from a first phase of analysis and then building interpretation with additional analysts (the third and fourth authors), this team of researchers added rigour to the data interpretation and to the study more broadly. As articulated earlier, our interpretations were framed by student-centred learning theory (Boud \& Soler, 2016) and interpretive phenomenology (Smith et al., 2009), and guided by the study question about students' experiences of successfully repeating a nursing course and achieving success after failure. Discussions with the student participants regarding the interpretations further supported the trustworthiness of findings.

\section{Findings}

Our findings reveal a multi-phased student experience beginning with being unsuccessful and feeling uncomfortable, then finding confidence, and finally cultivating a new (successful) identity. Central themes of seeking feedback and building study habits were part of the process, which are supported with participant comments with pseudonyms used for student names and discussed in light of the literature in more detail to follow.

\section{Feeling Uncomfortable}

The experience of discomfort was viewed as the starting place in a process towards success after failure. For some, this discomfort was articulated as a "wake-up call" and the realization that they were learning new things and would need to employ some new strategies to succeed. Jasmin described having come into the program with the history of ease and success in previous educational experiences, describing herself as feeling unprepared for the effort required:

I was the student in high school and junior high, [who] floated. I just ... I got good marks easily, so looking back I definitely didn't try as hard as I should have.

The self-reflection and awareness of discomfort was a motivator to both feel better in the students' body and mind, and to seek solutions and practical ways to overcome the sensation. This process was seen as both challenging and positive for learning and growth. As Vanessa explained:

I think I just didn't feel comfortable. Like, I didn't feel comfortable saying, hey, I'm struggling here. I don't feel I know what I'm doing. I think just admitting it is the worst, but the best thing I did for myself. 
For others the self-reflection inspired distress, and a feeling of hopelessness. For instance, according to Jon: "Well, what's even the point? What are they [instructors] going to do at this point?" When asked why they did not seek help, shame and embarrassment surfaced. Jon elaborated:

I think it's also that students don't know what support they can get. If I don't know how I can be supported by my prof, then going to talk to them, well, why am I going to go and talk to them?

A sense of ambivalence and general lack of motivation to study was described as the reason for not seeking help and for others a semblance of shame. For instance, Jasmin said:

So I should have kind of known better. But even in high school I never asked for help or anything, I just kind of floated by. Yeah, I probably wouldn't [have pursued help or assistance]. I don't really know why.

Fear of the unknown also featured in the experience of discomfort that moved students from failure to success. For students who may have never imagined they might fail or previously never sought additional help from an instructor, even a request from an instructor to come to their office or to meet after class prompted a feeling of discomfort in some and intensive self-reflection in others. The invitation to meet with an instructor to discuss the student's challenges in a course was a difficult and, at times, crucial turning point. The invitation was described as an important experience that gave the students pause for reflection. Alli explained the invitation in this way:

I think being told to come to [the instructor's] office, you know, being told instead of asked ... the experience could have been different, it was all just really hard. I don't know if the outcome [failing] would have changed, but the experience just could have been better!

\section{Finding Confidence}

Overcoming fear and intimidation, deciding to get help, and building successful study habits served to rebuild confidence that had become shattered in failure. Invitations to meet with instructors provided an opportunity to take a more reflective stance on their learning experience and habits. Following a failure, some students became open to accepting that they needed to change their mindset and habits to be successful. Fatima described understanding that something had to change for her to be successful in her next attempt at the course. She explained:

But I decided to do it again, and I decided to study more, to get some help and I decided to finish this thing, get over with it.

Fatima initially found the process of failing "frustrating and devastating at times, even though I knew I would fail," but then shifted to viewing the process as a part of her success. She recognized that having goals of further studies motivated her to find a way forward to achieve those goals. After waiting a semester to retake a failed course, Fatima returned with a renewed sense of her goals for herself and her professional life, she articulated:

I can still do it and that made me more motivated. I want to be somebody else that helps people and knows what she does, not just pass and give medicine that she doesn't even know what it is, right?"

She attributes her success to finding confidence through becoming more strategic, claiming she would give the following advice to others - to recognize that if 
it takes longer for you to study, then take more time to study. It doesn't matter if "they" study for an hour and get A's, if you have to study for 8 hours to get an A, then study for 8 hours.

Building confidence through the struggle and sense of accomplishment were hard fought rewards of a challenging journey. Alex explained how "it made me feel a bit better ... like I kind of earned that good mark."

\section{Building Study Habits}

Through self-appraisal, the intentional reflection on their habits, beliefs, and values, students in our study determined they were capable of learning what they needed to be successful. Following reflection and honest appraisal of their habits, students established plans for how they would achieve the requirements. When facing a failure or having failed, they were challenged by their self-appraisals and a sense of being blocked by fear and confusion about their study habits. Once acknowledged, honest self-appraisal and realistic study habits aided them in gaining expected foundational knowledge in their nursing education. Participants identified that they had not previously developed effective, realistic approaches to study and had routinely attributed their failings to not having memorized content, rather than to having ineffective study habits.

Without effective study habits, students did not know where to begin to take steps toward success; instead they tried the same things, expecting new and better results, continuing in vicious circles. Alli, who experienced confusion as to what to do next, stated:

Okay, I'm ... "I don't know what to do now. I don't know why did this happen?" And then I cried a lot and I went for a run and during the run I thought, you know what, I was missing something. I didn't know what I was missing."

Jordan reflected on her history of not studying in high school and her frustrating realization that she was not meeting expectations:

And I didn't know how to study. I was a straight A student before that, and the way I was studying before just wasn't [working] ... I wasn't able to do that with biology. So that was the issue for me ... I couldn't study how I was doing, like, my whole life. I never really studied in high school.

As Alex and several other participants found themselves struggling, their self-appraisals of their study habits proved to be inaccurate. In their view, they had been studying long hours to the point of exhaustion yet were not getting the return on this investment of time. When Alex failed the course and began a process of self-appraisal, she recalled:

And then I was, like, “oh, I wasn't really studying." Even though I was reading the textbook, I was doing things that I thought were working, and it was me studying, but it really wasn't ... that was how it felt. Because I was putting the time in, and I was doing the stuff, but it wasn't sitting with me.

Ben recalled that during the time leading up to and then following his course failure, he was starting to realize that his approach to studying was not effective:

It didn't work last time with the things that I did. I'm thinking I'm going to do differently, and then I don't know how ... but I just remember that I knew that I had to do something different. 
Alli added:

Finding your motivation and knowing your learning strategy, that's the most important thing. And if it takes longer for you to study, then take more time to study."

Participants talked through the experience of realizing that they were able to impact their success by learning ways and habits of studying. Many found this realization an empowering point in their learning and career development, one that led them to new ways of reading, observing, and note taking, and towards newfound confidence. Having successfully completed her nursing degree after overcoming a failure late in the program, Vanessa stated:

So the next time, I read the modules and the answers, but then I went to the textbook, and then looked at the figure, and read everything and highlighted. So that way, that was much, much better.

Fatima explained further,

I found that in third year I used my text [book] more ... I felt more confident the second time ... The second time you just get more confidence in yourself."

\section{Seeking Feedback}

Seeking help assisted students to discover the study habits that worked best for them and for their eventual success in the course. Jon enthused:

I've got the brains, but the problem was I did not have the study habits. I really didn'tand that screwed me immensely. When I worked this out, it was so easy for me going forward.

Jordan found, through her failure experience and over time, that asking for help was essential to success, though it was difficult and unfamiliar at first:

I was just never one to go ask for help. I just tried to just do it myself. And now I realise in third year, that's what you need to do.

Alex reflected on the challenge to students' ego in seeking help:

I think we got honestly awestruck in first year that we were like, I don't need to seek help, oh gosh I need some help, but I don't want to because I am proud.

Students claimed that while they eventually recognized the value of seeking feedback and went on to do so, their false hopes, fears, and lack of confidence held them back. On reflection, they all wished feedback and a path toward seeking help would have been offered directly to them and much earlier in their program so that they could have adjusted their habits earlier. Jon added:

I know I needed help but I did not go get the help because I didn't feel I could get enough help to make any difference.

\section{Cultivating a New Identity}

The majority of study participants failed a nursing course during the second year of their program. At the site of this study, second-year nursing program courses concentrate on core nursing requirements that are heavily influenced by sciences (pathophysiology and pharmacology), as well as a first major clinical practice placement where students are introduced to the application of fundamental nursing skills in real life clinical situations. Many of the students indicated that, during this critical and transitional period of their studies, they were also struggling 
with issues of personal identity, issues of self-efficacy, and the assumption of an identity as a mature university undergraduate. Their perceptions of the beliefs of a mature identity were of one who is able to self-moderate, self-control, and self-manage. This in-control identity was important in terms of time management, as well as their identity development as future nurses, and influenced the development of study habits beyond those accessible to them before starting university. According to Vanessa,

I was new into the university, I was young, I started doubting myself in everythingincluding my capabilities, because of the increased workload expected in my [nursing] courses.

Jayda reflected on the maturing process and identity formation in this way:

It seems that my generation is going through like this extended childhood almost, like we are teenagers. There is a second teenage year kind of thing where, the 18 and late 20s, we are still kids anyway. I wasn't 18, so I should have known better. But even in high school, I never asked for help or anything. I just kind of floated by. I know I can do better; I know I can excel, but I just need that motivation, and I need to tell myself that I can do it.

During this introspective process of self-appraisal and struggles, many students were not able to manage their schedules and time commitments effectively. Before they realized how far behind they were, or that they had not achieved some fundamental steps of learning, their courses were coming to an end, and they were inadequately prepared to pass their exams or final assignments.

Other students struggled with an inflated sense of their capabilities; they may have never failed any courses in the past and had been successful in their first year of study at the university. For some, this led to complacency in their studies and unwillingness to seek extra help and guidance when needed. Alex noted,

I thought I'd prepared well-'cause I did. But going into the review period, I discovered I did not know most of the stuff. I was just freaking out and reading the questions wrong ... and I have never failed a course in my whole life!

Jayda confessed that she had never understood her own study habits or established routines that worked for her in preparation, review, and completion of tasks, including in-class participation or presence. She made assumptions that her previous habits and casual approach would suffice:

I didn't pay attention in lecture. I was sitting there texting and chatting with my friends. And I was not paying attention. Again, I was, like, too confident that I'm going to pass, I'm too smart, I'm not going to fail.

Jayda continued,

I didn't know I was a visual learner and I had to look at the pictures and draw my own drawings and do the concept mapping, make connections, and write them down. I didn't know that, and so the second time, I thought I would do something different and it turned out good for me. It didn't work last time with the things that I did. I'm going to do things differently now. I don't know how I did realize it, but I just remember that I knew I had to do something different.

The students' cultivation of new identities as more mature, self-aware and successful started by acknowledging their weaknesses and declaring a willingness to seek out additional help. 
And many students, after the first failure, did seek out help from classmates, friends, and instructors - assistance that enabled them to understand who they were and their true capabilities. For most, it was this help and feedback that eventually made a difference when repeating their courses. Ben explained:

For me, as I said, maybe I was too proud of myself. I felt I wouldn't need another person's help, "I can do this." Maybe that was one reason and as soon as I got over this and sought help, things started working out well.

\section{Discussion}

Student trust and awareness of our willingness to help will grow if we regularly reveal our desire to do so (Lammers, 2016, p. 7).

In their experiences of moving from failure to success, nursing students who had previously failed a course explained what happened as they bridged what, at times, seemed like a gap in their very sense of themselves. Bridging the gap meant feeling uncomfortable, finding confidence, and cultivating a new identity, a process that arose from initial fear, frustration, and confusion after failing a nursing course. These experiences led students to seek help and build study and time management habits that guided them towards eventual success. Ultimately, the experience of seeking help and identifying failings supported students to form a new "successful" identity. Through increased awareness and a newfound confidence, success became possible for the students. For all who achieved success after failure, seeking feedback and support was instrumental in the process. One important finding in the study was the insistence from participants that they would initially not seek out feedback from educators, unless such feedback is initiated by educators themselves. A number of reasons for this insistence emerged, including a sense of identity that did not include the idea of failure or needing help.

Many aspects of personal identity also emerged in the movement from failure to success. In several cases, students externalized their habits from their identities and paradoxically established more productive and useful habits that bolstered their sense of self-efficacy, leading to their constructing a new identity and willingness to do what it takes to be successful. Skills in realistic self- appraisal were instrumental in establishing new study habits and to forming more mature identities as students. All these experiences led the students to bridge the gap that left them confused and without the necessary habits, skills, and knowledge to be successful. It may be that, as in Wibrowski, Matthews, and Kitsantas's (2017) longitudinal study, through help-seeking, the series of self-management and study habits can be established in an enduring manner. O'Neill (2012) also describes the value of self-efficacy as a skill set best developed in the pre-registration phase of nursing education, citing results from a Scottish preparatory module designed to help students identify new styles of learning and provide them with added confidence and competence to complete their studies. Evaluation of the long term outcomes from implementing this modular learning for nursing students will add to the understanding. The longer-term benefits and qualities of the turning-point experience in moving from failure to success will be important areas of future study.

The proactive steps and role of nurse educators to bridge the gap were also identified in our study. It ultimately took the initiative and role of a trusted educator to initiate feedback and to provide a more realistic appraisal of study habits and suggestions to build student self-awareness. Trust appears to be an essential ingredient in the experience of this feedback and guidance towards self-awareness and new skills (Lammers, 2016). Developing trust begins on the first day of class 
and even before the class or clinical starts. How an educator designs a course sets the tone for this caring and trust. An open learning environment and other pedagogical practices establish and build trust in the teaching-learning process (Gillespie, 2005). Lammers (2016) found that several independent and interacting qualities of the student, instructor, and environment influenced help seeking in struggling undergraduate students. Most of the facilitators to seeking help were educator qualities, including having a caring and encouraging attitude, knowing students' names, being open and willing to help, being flexible and available (such as holding office hours, providing a phone number, and using and answering email) (Lammers, 2016). These qualities set up a proactive environment for help seeking and responsiveness to the invitation for feedback.

A proactive stance is also needed for educators to actively support at-risk students early in a nursing program (Elliot, 2016; Harding, 2012; Jeffreys, 2014; Liem \& Martin, 2012; Tower et al., 2015). Proactive strategies to identify students early and provide interventions at key transitional times in a program can work to prevent failure or withdrawal (Jeffreys, 2014). As this study demonstrated, and literature supports, students frequently do not seek out help from educators until it is too late to alter a declining academic situation (Jeffreys, 2014). What constitutes an at-risk student may be related to grades, attendance, participation, or the educator recognizing a pattern of behaviour (Tower et al., 2015). This early and proactive intervention may best be delivered as a form of feedback that supports careful self-appraisal and builds self-efficacy and study habits (Bulfone et al., 2019; Lammers, 2016). Awareness of nursing student self-efficacy can also be strengthened through a validated and reliable measure (Bulfone et al., 2019). Instruments for understanding nursing student self-efficacy and other forms of feedback used to support successful study habits are avenues worth exploring in cohort and longitudinal analyses to learn more about student success from earlier failure.

\section{Limitations}

A small, localized, interpretive study such as this project has inherent limitations. Participants entered the study at a point in their experience of success after failure and with their own biases toward help-seeking along the journey. Participants at other points in the journey from failure to success would invariably offer different insights. Students who found success after failure but who did not participate in the study may have different insights about their journey from failure to success. The study was also limited by our frame on student-centred education, with an emphasis on educational psychology and individual identity formation. A critical, ecological, or social perspective would offer additional insights to this study. Further inquiry into other factors shaping the movement from failure to success will benefit the study of nursing education and pedagogical practice.

\section{Conclusions}

By listening to nursing students' often hidden aspects of course failure, this project uncovered how student identity and habits were part of the experience of moving from failure to success. The movement from failure to success involves a journey through discomfort and fear to acceptance of help and eventually to rebuilding one's identity as successful. Student-centred, focused, and purposeful connection may play a role in nurse educators' proactive support for student transitions from failure to success. An instructor's very invitation to discuss learning challenges can be a turning point in building students' confidence, self-efficacy, self-awareness, and skills, particularly when arising from a trusting relationship. Further inquiry is needed to examine how aspects of identity are specifically forged in this trusting relationship, key aspects of 
the invitation for additional feedback, and how confidence can be built to support help seeking and the establishment of new study habits. Taken together, this growing area of scholarship and practice will deepen our knowledge of how best to support students to either avoid failure or move from failure to success. 


\section{References}

Andrew, S., Mcvicar, A., Zanganeh, M., \& Henderson, N. (2015). Self-efficacy and relevance of bioscience for nursing, midwifery and healthcare students. Journal of Clinical Nursing, 24(19-20), 2965-2972. https://doi.org/10.1111/jocn.12933

Attard, A., Di Ioio, E., Geven, K., \& Santa, R. (2010). Student centered learning: An insight into theory and practice. Education International; The European Student Union.

Bastable, S. (2018). Nurse as educator: Principles of teaching and learning for nursing practice (5th ed.). Jones \& Bartlett Learning.

Boud, D., \& Soler, R. (2016). Sustainable assessment revisited. Assessment \& Evaluation in Higher Education, 41(3), 400-413. https://doi.org/10.108002602938.2015.1018133

Bulfone, G., Vellone, E., Maurici, M., Macale, L., \& Alvaro, R. (2019). Academic self-efficacy in bachelor-level nursing students: Development and validation of a new instrument. Journal of Advanced Nursing. https://doi.org/10.1111/jan.14226

Canadian Nurses Association. (2015). Framework for the practice of registered nurses in Canada (2nd ed.).

Dante, A., Valoppi, G., Saiani, L., \& Palese, A. (2011). Factors associated with nursing students' academic success or failure: A retrospective Italian multicenter study. Nurse Education Today, 31(1), 59-64. https://doi.org/10.1016/j.nedt.2010.03.016

da Silva, T. L., \& Ravindran, A. V. (2016). Contributors to academic failure in postsecondary education: A review and a Canadian context. International Journal of NonCommunicable Diseases, 1, 9-17. https://doi.org/10.4103/2468-8827.184854

Denzin, N. K., \& Lincoln, Y. S. (2017). Handbook of qualitative research (5th ed.). Sage.

DiCicco-Bloom, B., \& Crabtree, B. F. (2006). The qualitative research interview. Medical Education, 40, 314-321.

Docherty, A. (2018). Failing to fail in undergraduate nursing: Understanding the phenomenon. Nursing Education Perspectives, 39(6), 335-342. https://doi.org/10.1097/01.nep.0000000000000350

Elliot, C. (2016). Identifying and managing under performing in nursing students. British Journal of Nursing, 25(5), 250-255. https://doi.org/10.12968/bjon.2016.25.5.250

Fay, M., Barnett, E., \& Chavarín, O. (2017). How states are implementing transition curricula: results from a national scan. CCRC research brief. Columbia University Research Center.

Finch, J., \& Taylor, I. (2013). Failure to fail? Practice educators' emotional experiences of assessing failing social work students. Social Work Education: The International Journal, 32(2), 244-258. https://doi.org/10.1080/02615479.2012.720250

Freeman, C., \& All, C. (2017). Academic support programs utilized for nursing students at risk of academic failure: A review of the literature. Nursing Education Perspectives, 38(2), 69-74. https://doi.org/10.1097/01.nep.0000000000000089 
Freitas, F. A., \& Leonard, L. J. (2011). Maslow's hierarchy of needs and student academic success. Teaching and learning in nursing, 6(1), 9-13. https://doi.org/10.1016/j.teln.2010.07.004

Gillespie, M. (2005). Student-teacher connection: A place of possibility. Journal of Advanced Nursing, 52(2), 211-219.

Greenberg, K. H., Sohn, B. K., Greenberg, N. B., Pollio, H. R., Thomas, S. P., \& Smith, J. T. (2019). The phenomenological heart of teaching and learning: Theory, research, and practice in higher education. Routledge.

Handwerker, S. M. (2018). Challenges experienced by nursing students overcoming one course failure: A phenomenological research study. Teaching and Learning in Nursing, 13(3), 168-173. https://doi.org/10.1016/j.teln.2018.03.007

Harding, M. (2012). Efficacy of supplemental instruction to enhance student success. Teaching and Learning in Nursing, 7(1), 27-31. https://doi.org/10.1016/j.teln.2011.07.002

Jeffreys, M. R. (2012). Nursing student retention: Understanding the process and making a difference (2nd ed.). Springer.

Jeffreys, M. (2014). Student retention and success: Optimizing outcomes through holistic competence and proactive inclusive enrichment. Teaching and Learning in Nursing, 9(4), 164-170. https://doi.org/10.1016/j.teln.2014.05.003

Karsten, K., \& DiCicco-Bloom, B. (2015). Corrigendum to "Acknowledging the academic rigor of associate degree nursing education: A grounded theory study of overcoming failure." Teaching and Learning in Nursing 9 (2014) 153-163. Teaching and Learning in Nursing, 1(10), 53. https://doi.org/10.1016/j.teln.2014.10.004

Kerssen-Griep, J., \& Terry, C. L. (2016). Communicating instructional feedback: Definitions, explanations, principles, and questions. In P. L. Witt (Ed.), Communication and learning (pp. 287-318). De Gruyter Mouton. https://doi.org/10.1515/9781501502446

Kirschner, P. A. (2017). Stop propagating the learning styles myth. Computers and Education, 106, 166-171. https://doi.org/10.1016/j.compedu.2016.12.006

Knepp, K. A. F. (2012). Understanding student and faculty incivility in higher education. Journal of Effective Teaching, 12(1), 33-46.

Lammers, W. J. (2016). Why won't they ask us for help? The Teaching Professor, 30(4), 5-7.

Lancia, L., Caponnetto, V., Dante, A., Mattei, A., La Cerra, C., Cifone, M., \& Petrucci, C. (2018). Analysis of factors potentially associated with nursing students' academic outcomes: A thirteen-year retrospective multi-cohort study. Nurse Education Today, 70, 115-120. https://doi.org/10.1016/j.nedt.2018.08.020

Lancia, L., Petrucci, C., Giorgi, F., Dante, A., \& Cifone, M. G. (2013). Academic success or failure in nursing students: Results of a retrospective observational study. Nurse Education Today, 33(12), 1501-1505. https://doi.org/10.1016/j.nedt.2013.05.001

Liem, G. A. D., \& Martin, A. J. (2012). The motivation and engagement scale: Theoretical framework, psychometric properties, and applied yields. Australian Psychologist, 47, 313. https://doi.org/10.1111/j.1742-9544.2011.00049.x 
Litchfield, J. (2001). Supporting nursing students who fail: A review of lecturers' practice. Nurse Education in Practice, 1, 142-148.

Luhanga, F. L., Larocque, S., MacEwan, L., Gwekwerere, Y. N., \& Danyluk, P. (2014). Exploring the issue of failure to fail in professional education programs: A multidisciplinary study. Journal of University Teaching \& Learning Practice, 11(2). http://ro.uow.edu.au/jutlp/vol11/iss2/3

Miller, C. M. (2017). Diversity matters: A case study of the cultural components of three Ontario college leadership development programs. The University of Western Ontario.

Olsen, J. (2017). Integrative review of admission factors related to associate degree nursing program success. Journal of Nursing Education, 56(2), 85-93. https://doi.org/10.3928/01484834-20170123-05

O’Neill, E. (2012). Ready for university: a preparatory module for pre-registration nursing students is reaping benefits. Nursing Standard, 26(46), 64. https://doi.org/10.7748/ns2012.07.26.46.64.p8967

Parker, M., \& Winstone, N. E. (2016). Students' perceptions of interventions for supporting their engagement with feedback. Practitioner research in higher education, 10(1), 53-64.

Sadler, G. R., Lee, H. C., Lim, R. S., \& Fullerton, J. (2010). Recruitment of hard-to-reach population subgroups via adaptations of the snowball sampling strategy. Nursing and Health Sciences, 12(3), 369-374. https://doi.org/10.1111/j.1442-2018.2010.00541.x

Schneider, M., \& Preckel, F. (2017). Variables associated with achievement in higher education: A systematic review of meta-analyses. Psychological Bulletin, 143(6), 565-560. https://doi.org/10.1037/bul0000098

Smith, J. A., Flowers, P., \& Larkin, M. (2009). Interpretative phenomenological analysis: Theory, method and research. Sage.

Smith, J. A., \& Osborn, M. (2003). Interpretative phenomenological analysis. In J. A. Smith (Ed.), Qualitative psychology: A practical guide to research. Sage.

Thorne, S. (2013). Interpretive description. In C. T. Beck (Ed.), Routledge international handbook of qualitative nursing research (pp. 295-306). Routledge.

Tower, M., Walker, R., Wilson, K., Watson, B., \& Tronoff, G. (2015). Engaging, supporting and retaining academic at-risk students in a bachelor of nursing: Setting risk markers, interventions and outcomes. The International Journal of the First Year in Higher Education, 6(1), 121-135. https://doi.org/10.5204/intjfyhe.v6i1.251

Vinales, J. (2015). Exploring failure to fail in pre-registration nursing. British Journal of Nursing, 24(5), 284-288. https://doi.org/10.12968/bjon.2015.24.5.284

Wibrowski, C. R., Matthews, W. K., \& Kitsantas, A. (2017). The role of a skills learning support program on first-generation college students' self-regulation, motivation, and academic achievement: A longitudinal study. Journal of College Student Retention: Research, Theory \& Practice, 19(3), 317-332. https://doi.org/10.1177/1521025116629152

Yepes-Rios, M., Dudek, N., Duboyce, R., Curtis, J., Allard, R. J., \& Varpio, L. (2016). The failure to fail underperforming trainees in health professions education: A BEME 
Quality Advancement in Nursing Education - Avancées en formation infirmière, Vol. 6, Iss. 1 [2020], Art. 6

systematic review: BEME Guide No. 42. Medical Teacher, 38(11), 1092-1099.

https://doi.org/10.1080/0142159x.2016.1215414 